\title{
STAT5 proteins are involved in down-regulation of iron regulatory protein 1 gene expression by nitric oxide
}

\author{
Rafal Radoslaw STARZYNSKI*, Ana Sofia GONÇALVES $\dagger$, Françoise MUZEAU†, Zofia TYROLCZYK*, Ewa SMUDA*, \\ Jean-Claude DRAPIER $\neq$, Carole BEAUMONT† and Pawel LIPINSKI*1 \\ *Department of Molecular Biology, Institute of Genetics and Animal Breeding, Polish Academy of Sciences, Jastrzebiec, ul. Postepu 1, 05-552 Wolka Kosowska, Poland, $\dagger$ INSERM \\ U773, Centre de Recherche Biomédical Bichat Beaujon CRB3, Faculté Xavier Bichat, BP416, 16 Rue Henri Huchard, 75870 Paris cedex 18, France, and ¥CNRS, Institut de Chimie des \\ Substances Naturelles, 91190 Gif-sur-Yvette, France
}

\begin{abstract}
RNA-binding activity of IRP1 (iron regulatory protein 1) is regulated by the insertion/extrusion of a $[4 \mathrm{Fe}-4 \mathrm{~S}]$ cluster into/from the IRP1 molecule. NO (nitic oxide), whose ability to activate IRP1 by removing its [4Fe-4S] cluster is well known, has also been shown to down-regulate expression of the IRPI gene. In the present study, we examine whether this regulation occurs at the transcriptional level. Analysis of the mouse IRPI promoter sequence revealed two conserved putative binding sites for transcription factor(s) regulated by $\mathrm{NO}$ and/or changes in intracellular iron level: Sp1 (promoter-selective transcription factor 1) and MTF1 (metal transcription factor 1), plus GAS (interferon- $\gamma$-activated sequence), a binding site for STAT (signal transducer and activator of transcription) proteins. In order to define the functional activity of these sequences, reporter constructs were generated through the insertion of overlapping fragments of the mouse IRPI promoter upstream of the luciferase gene. Transient expression assays following transfection of $\mathrm{HuH} 7$ cells with these plasmids revealed that while both the Sp1 and GAS sequences are involved in
\end{abstract}

basal transcriptional activity of the IRPI promoter, the role of the latter is predominant. Analysis of protein binding to these sequences in EMSAs (electrophoretic mobility-shift assays) using nuclear extracts from mouse RAW 264.7 macrophages stimulated to synthesize NO showed a significant decrease in the formation of Sp1-DNA and STAT-DNA complexes, compared with controls. We have also demonstrated that the GAS sequence is involved in NO-dependent down-regulation of IRPI transcription. Further analysis revealed that levels of STAT5a and STAT5b in the nucleus and cytosol of NO-producing macrophages are substantially lower than in control cells. These findings provide evidence that STAT5 proteins play a role in NO-mediated down-regulation of IRPI gene expression.

Key words: iron metabolism, iron regulatory protein 1 (IRP1), nitric oxide, promoter regulation, signal transducer and activator of transcription (STAT), transcription factor.

\section{INTRODUCTION}

In mammals, cellular iron homoeostasis is largely co-ordinated at the post-transcriptional level through the action of two cytoplasmic IRPs (iron regulatory proteins) (IRP1 and IRP2). They function by binding to RNA stem-loop structures, known as IREs (iron-responsive elements), located in the 5'- or 3'-untranslated regions respectively of specific mRNAs that code for ferritin and transferrin receptors. The activity of IRPs is modulated by changes in intracellular iron concentrations, becoming activated as translational repressors and/or molecules conferring mRNA stability by low iron and inactivated by high levels of iron in the LIP (labile iron pool) [1]. The inactive IRP1 has a secondary function as cytosolic aconitase when co-ordinating a [4Fe-4S] cluster, which masks the IRE-binding site. It has long been held that IRP1 is a major post-transcriptional regulator that controls iron metabolism in response to fluctuations in intracellular iron. However, recent studies on $\mathrm{KO}$ (knockout) IRPI [2] and $\mathrm{KO}$ IRP2 mice [3,4] strongly suggest that IRP2, rather than IRP1, is responsible for maintenance of the constitutive body iron balance. The new concept of IRP1 as a molecular target responding preferentially to stimuli other than iron-related challenges is now under debate $[5,6]$. Indeed, the two activities of IRP1 have been shown to be modulated by NO (nitric oxide) [7,8], oxidative stress [9,10], phosphorylation [11] and hypoxia/reoxygenation [12].

NO and/or NO-derived species appear to be chemical messengers able to induce a broad spectrum of post-translational modifications of the IRP1 molecule. First, NO may act directly on the $[4 \mathrm{Fe}-4 \mathrm{~S}]$ cluster of IRP1, inducing its gradual disassembly and removal, favouring the IRE-binding conformation of the protein $[13,14]$. Secondly, nitration of IRP1, reported in vitro following its exposure to peroxynitrite [14] and in NO- and superoxide $\left(\mathrm{O}_{2}{ }^{--}\right)$producing macrophages [15], has been shown to prevent IRP1 activation. Lastly, NO is also responsible for the down-regulation of IRPI expression at both mRNA and protein levels [16].

Needless to say, modulation of IRP1 function is an important element but not the sole contributor in a complex network of interactions between NO and intracellular iron (reviewed in $[17,18])$. Besides IRP1, IRP2 has been also shown to be regulated by NO $[19,20]$. It is also important to recall that one of the most apparent hallmarks of NO action originally described by Hibbs et al. [21] is depletion of intracellular iron. Recently, a mechanism of NO-induced iron loss involving glutathione and multidrug resistance-associated protein 1 has been proposed [22]. Another common feature of cells exposed to NO is the formation

Abbreviations used: 1400W, N-[3-(aminonethyl)benzoyl]acetamide; DETA/NO, diethylentriamine NONOate (diazeniumdiolate); DFO, desferrioxamine ${ }^{\circledR}$; DTT, dithiothreitol; EMSA, electrophoretic mobility-shift assay; FAC, ferric ammonium citrate; FCS, fetal calf serum; GAPDH, glyceraldehyde-3-phosphate dehydrogenase; IFN- $\gamma$, interferon- $\gamma$; GAS, IFN- $\gamma$-activated sequence; IRE, iron-responsive element; IRP, iron regulatory protein; KO, knockout; LIP, labile iron pool; L-NMMA, L-N $N^{G}$-monomethyl-L-arginine; LPS, lipopolysaccharide; MRE, metal responsive element; MTF1, metal transcription factor 1; NOS2, nitric oxide synthase 2; ONPG, o-nitrophenyl- $\beta$-D-galactopyranoside; RT, reverse transcriptase; Sp1, promoter-selective transcription factor 1 ; STAT, signal transducer and activator of transcription; SV40, simian virus 40; TF, transcription factor

1 To whom correspondence should be addressed (email P.Lipinski@ighz.pl). 
of iron-nitrosyl complexes, with multiple haem and non-haem iron proteins inhibiting key enzymes in DNA synthesis and mitochondrial respiration (reviewed in 23,24]). Finally, NO has been reported to be a strong inducer of haem oxygenase expression at both the transcriptional [25] and post-transcriptional level [26].

In the present study, we focused on NO-mediated downregulation of IRP1, an effect that may be of considerable biological importance, especially under conditions of sustained NO synthesis, because it could reduce the amount of the protein available for post-translational modification. The biological mechanisms underlying the NO-induced decrease in IRP1 expression are unknown, although it has been suggested that NO can modify transcriptional activity of the $I R P I$ gene [16]. Indeed, accumulating evidence suggests that NO affects gene expression at the transcriptional level [27] by modulating the activities of various TFs (transcription factors) such as NF- $\kappa \mathrm{B}$ (nuclear factor $\kappa \mathrm{B}$ ) [28], AP-1 [29], Sp1 [30], HIF-1 (hypoxia-inducible factor-1) [31] and STAT (signal transducer and activator of transcription) [32]. Here, we sought to locate putative binding sites for TFs regulated by NO and/or changes in intercellular iron level. Through examination of the nucleotide sequence of the mouse $I R P I$ promoter (GenBank ${ }^{\circledR}$ accession no. AJ427344), we identified the following conserved motifs: one Sp1 sequence, one MRE (metal responsive element) and one binding site for STAT family proteins GAS [IFN- $\gamma$ (interferon- $\gamma$ )-activated sequence] $\}$. Functional analysis of the IRP1 promoter region and analysis of these putative TFbinding sites by EMSA (electrophoretic mobility-shift assay) using nuclear extracts from NO-producing RAW 264.7 macrophages indicate that the GAS is an important regulatory element responsible for down-regulation of IRPI expression by NO.

\section{EXPERIMENTAL}

\section{Materials}

DMEM (Dulbecco's modified Eagle's medium) was obtained from Gibco-BRL. Low endotoxin FCS (fetal calf serum), FAC (ferric ammonium citrate), DFO (desferrioxamine ${ }^{\circledR}$ ) and LPS (lipopolysaccharide) from Escherichia coli (serotype O55:B5) were purchased from Sigma (St. Louis, MO, U.S.A.). Murine recombinant IFN- $\gamma$ was from RandD Systems. 1400W $\{N-[3-$ (aminomethyl)benzoyl]acetamide $\}$, L-NMMA (L- $N^{\mathrm{G}}$-monomethyl-L-arginine) and DETA/NO [diethylentriamine NONOate (diazeniumdiolate)] were purchased from Cayman Chemical Co. (Ann Arbor, MI, U.S.A.). Restriction and modification enzymes were from Invitrogen (Carlsbad, CA, U.S.A.). All oligonucleotides were synthesized by Invitrogen. Competent $E$. coli $\mathrm{DH} 5 \alpha^{\mathrm{TM}}$ cells, ONPG (o-nitrophenyl $\beta$-D-galactopyranoside) and Lipofectamine $^{\mathrm{TM}}$ were from Invitrogen. Luciferin was from Euromedex. All other chemicals were obtained from Sigma.

\section{Cell culture and treatment}

RAW 264.7 murine macrophages, a cell line established from a tumour induced by Abelson murine leukaemia virus, were obtained from the American Type Culture Collection (Rockville, MD, U.S.A.). Cells were cultured in DMEM containing $5 \%(\mathrm{v} / \mathrm{v})$ FCS and gentamicin $(50 \mu \mathrm{g} / \mathrm{ml})$ in $100 \mathrm{~cm}^{2}$ plastic culture flasks (Nunc) in a humidified atmosphere of $95 \%$ air and $5 \% \mathrm{CO}_{2}$ at $37^{\circ} \mathrm{C}$. For NOS2 (nitric oxide synthase 2) induction, RAW 264.7 macrophages were stimulated for $16 \mathrm{~h}$ with $20 \mathrm{units} / \mathrm{ml}$ IFN- $\gamma$ and $50 \mathrm{ng} / \mathrm{ml}$ LPS. In other experiments these cells were incubated with $250 \mu \mathrm{M}$ DFO and/or $100 \mu \mathrm{M}$ FAC for $24 \mathrm{~h}$. The human hepatoma cell line $\mathrm{HuH} 7$ was maintained in DMEM supplemented with $10 \%(\mathrm{v} / \mathrm{v}) \mathrm{FCS}, 50$ units $/ \mathrm{ml}$ penicillin and $50 \mu \mathrm{g} / \mathrm{ml}$ streptomycin.

\section{Nitrite measurement}

NO production was determined by quantifying nitrite, the stable end-product of NO, spectrophotometrically by a colorimetric assay. Briefly, $200 \mu \mathrm{l}$ of sample medium was reacted with $800 \mu \mathrm{l}$ of Griess reagent $(1 \%$ sulfanilamide and $0.1 \%$ naphthylethylenediamine), and the absorbance was measured at $543 \mathrm{~nm}$. Sodium nitrite was used as a standard.

\section{Plasmid constructs}

Two fragments from the IRPI promoter region were PCR amplified using two different forward primers: promIRP1F1 5'-CCGACGCGTCCCGACTAGACTGCAAGCTTCAGCCATC-3' (for the fragment encompassing -122 to $+73 \mathrm{bp}$ ) and promIRP1F2 5'-CCGACGCGTAGAAATCGGCTCTACACTTCCTGGGACTGAG (for the fragment encompassing -532 to $+73 \mathrm{bp}$ ) and the same reverse primer promIRP1R 3'-CCGCTCGAGCCGACTCCGCGCTCCTCCCACTGA-5'. The two PCR fragments of respectively 195 and $605 \mathrm{bp}$ were digested with XhoI/MluI and ligated to the XhoI/MluI-cleaved pGL2-basic vector (Promega, Madison, WI, U.S.A.) to create plasmids pGL2IRP1P0.1 and pGL2-IRPIP0.2 in which the IRPI promoter sequences were transcriptionally fused in the correct orientation to the luciferase reporter gene. To generate a third construct, pGL2-IRP1P0.3, a double-stranded oligonucleotide containing the upstream GAS sequence from the IRPI promoter (boldface) as well as $5^{\prime} \mathrm{KpnI}$ (underlined) and a $3^{\prime}$ MluI (underlined) restriction site $5^{\prime}$-CCGGGTACCAGGCATTTCTAGGAAAATAAGAACGCGTGCC-3' was inserted into the pGL2-IRPIP0.2 plasmid following $\mathrm{MluI} / \mathrm{KpnI}$ digestion to place it upstream of the $605 \mathrm{bp}$ fragment. The orientation and the integrity of all plasmids were verified by sequencing. Figure 1(B) shows a schematic representation of the luciferase reporter constructs used in the present study.

\section{Transfections and reporter gene assays}

Twenty-four hours before transfection, $\mathrm{HuH} 7$ cells were plated in six-well culture plates (Nunc) at $50-70 \%$ confluence. The cells were transiently transfected with $1 \mu \mathrm{g}$ of plasmid DNA using Lipofectamine ${ }^{\mathrm{TM}}$ reagent according to the manufacturer's recommendations. Cells were incubated, $6 \mathrm{~h}$ after transfection, with $250 \mu \mathrm{M}$ DETA/NO for $48 \mathrm{~h}$. After incubation the cells were harvested, total cellular extracts were prepared and luciferase activity was assessed using the Luciferase Assay System kit according to the manufacturer's instructions (Promega). As an internal control to assess transfection efficiency, cells were cotransfected with a reporter vector ( $\mathrm{pSV} \beta$-gal) containing the $\beta$-galactosidase gene driven by the SV40 (simian virus 40 ) virus promoter (Promega). Luciferase activities were normalized relative to co-expressed $\beta$-galactosidase activity values measured in a standard assay in which ONPG hydrolysis was quantified by absorbance at $420 \mathrm{~nm}$ using a Hitachi U-2000 spectrophotometer. As negative and positive controls for transient transfection experiments, the pGL2-basic vector without any promoter sequence and a pGL3 control vector containing the SV40 promoter were used respectively.

\section{EMSA}

Nuclear protein extracts were prepared from cells as previously described [33]. Three double-stranded DNA fragments, created 
A

A mouse

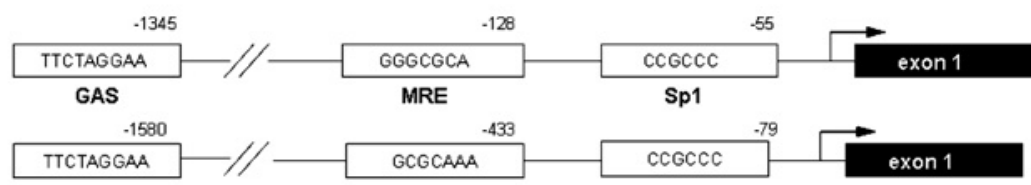

consensus TTCNNNGAA GNGRGCT $\operatorname{ccGcCC}$
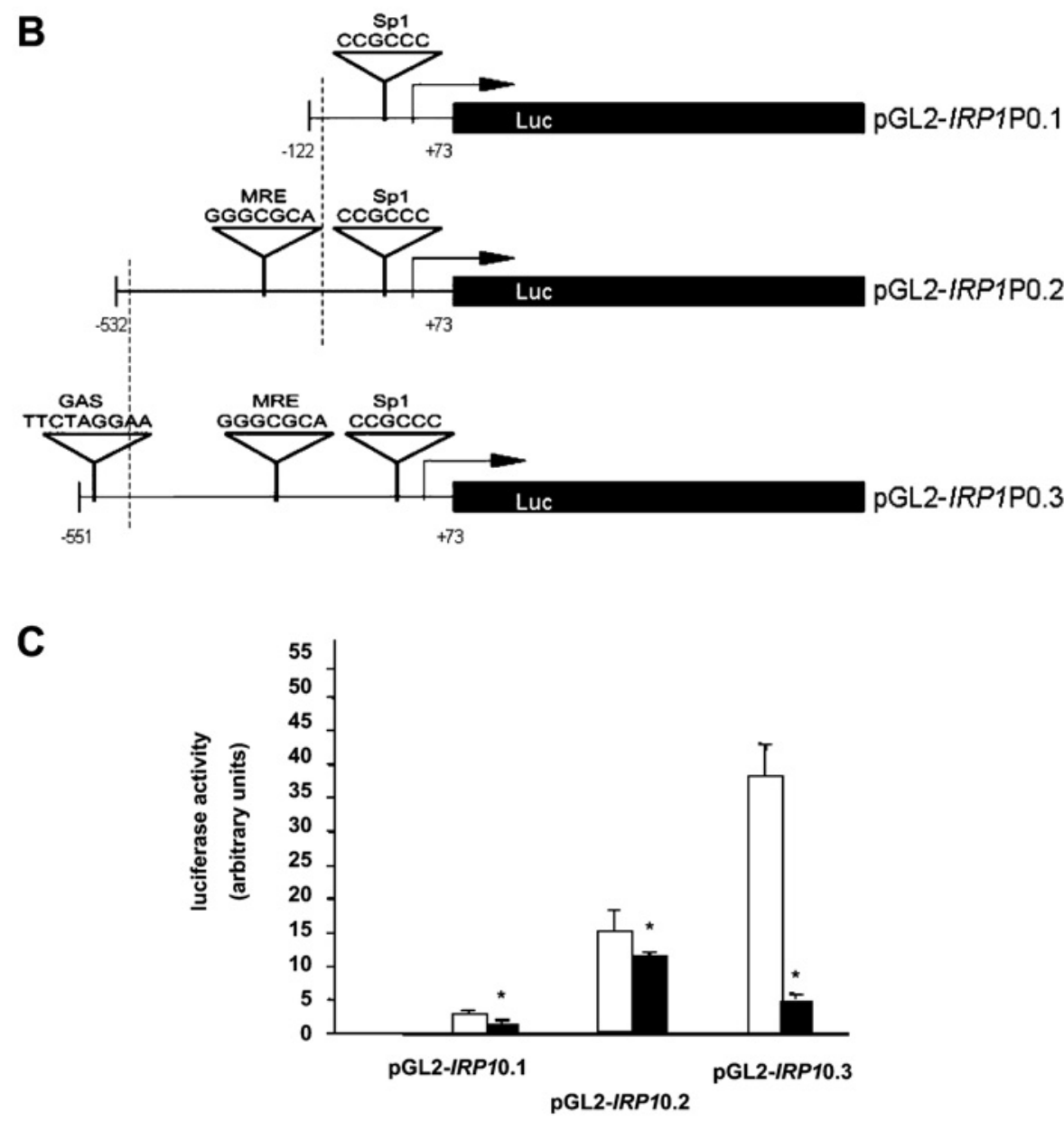

\section{Figure 1 Functional studies of the IRP1 promoter region}

(A) The location of putative binding sites for the TFs regulated by NO and/or changes in intracellular iron level in the mouse IRP1 promoter. The -2790 to +90 bp fragment of the mouse IRP1 gene (GenBank ${ }^{\circledR}$ accession no. AJ427344) was analysed using TESS software and the TRANSFAC database. The indicated sequences located at positions -61 to $-55 \mathrm{bp},-135$ to $-128 \mathrm{bp}$ and -1354 to -1345 bp upstream of the transcription initiation site, represent three potential cis-acting regulatory elements corresponding to Sp1, MRE and the GAS sequence respectively. The consensus sequences and the position of the above-mentioned putative binding sites in human IRP1 gene sequence (AL161783) are indicated. (B) Structure of reporter gene constructs used in transient transfection assays. All constructs were prepared using the pGL2-basic vector. Two overlapping fragments of the mouse IRP1 promoter sequence extending from -122 to $+73 \mathrm{bp}$ and -532 to $+73 \mathrm{bp}$ relative to the transcription start were amplified and cloned in front of the coding region of the luciferase gene to generate two constructs: pGL2-IRP1P0.1 and pGL2-IRP1P0.2 respectively. A third construct pGL2-IRP1P0.3 was generated by insertion of a $19 \mathrm{bp}$ fragment of the mouse IRP1 promoter containing the GAS sequence upstream of the -532 to +73 bp fragment in pGL2-IRP1P0.2. Sequences corresponding to the putative Sp1-, MTF1- and STAT-binding sites are shown. (C) Basal and N0-dependent transcriptional activity of mouse IRP1 promoter fragments. HuH7 cells were transfected with luciferase reporter gene constructs containing $194 \mathrm{bp}$ (pGL2-IRP1P0.1), $605 \mathrm{bp}$ (pGL2-IRP1P0.2) and $624 \mathrm{bp}$ (pGL2-IRP1P0.3) IRP1 promoter fragments as described in the Experimental section. After $5 \mathrm{~h}$, the cells were treated with $250 \mu \mathrm{M}$ DETA/NO (solid bars) or left untreated (open bars). After $48 \mathrm{~h}$, the cells were harvested, lysed and assayed for luciferase activity. $\beta$-Galactosidase activity produced by the co-transfected plasmid pSV40 $\beta$-gal was used to correct for transfection efficiencies and to normalize the luciferase activity of each sample. Results represent the means \pm S.D. for three separate experiments. Asterisks indicate a statistically significant decrease in promoter activity in N0-treated cells compared with non-N0-treated cells $\left({ }^{\star} P<0.05\right.$ ).

by annealing oligonucleotides, were used as probes: 5'-CCAGGCTCCGCCCCTCGGGG-3', 5'-CCCCGAGGGGCGGAGCCTGG-3'; 5'-GAAGGGAGGGCGCACCCGGACT-3', 5'-AGTCCGGGTGCGCCCTCCCTTC-3' and 5'-AAGGCATTTCTAGGAAAATAAGAT-3', 5'-ATCTTATTTTCCTAGAAATGCCTT- $3^{\prime}$. These sequences were identical with the following regions of the mouse IRPI promoter: -70 to -50 bp containing an Sp1binding site (underlined), -141 to -119 bp containing an MRE sequence (underlined) and -1363 to -1339 bp containing a GAS sequence (underlined). EMSAs were performed as described 
previously [33]. Briefly, all fragments were labelled with $\left[{ }^{32} \mathrm{P}\right] \mathrm{ATP}$ (NEN Life Science Products-DuPont, Bad Homburg, Germany) using T4 polynucleotide kinase (Fermentas). The radiolabelled probes $(0.1-0.5 \mathrm{ng})$ were incubated with nuclear protein extracts $(2.5 \mu \mathrm{g})$ for $20 \mathrm{~min}$ at room temperature in $20 \mu \mathrm{l}$ reaction mixtures containing $10 \mathrm{mM}$ Hepes (pH 7.9), $100 \mathrm{mM} \mathrm{KCl}, 1.5 \mathrm{mM}$ $\mathrm{MgCl}_{2}, 1 \mathrm{mM}$ DTT (dithiothreitol), $1 \mathrm{mM}$ EGTA and $10 \%$ glycerol. The specificity of DNA binding was determined by competition assays performed using a 25- or 50-fold excess of the unlabelled fragments. Reactions were examined by electrophoresis on nondenaturing $6 \%$ polyacrylamide gels prepared in a buffer composed of $45 \mathrm{mM}$ Tris ( $\mathrm{pH} 8.0), 45 \mathrm{mM}$ borate and $1 \mathrm{mM}$ EDTA. After running for $2 \mathrm{~h}$, the gels were dried and the radioactive signal visualized using a Bio-Rad Molecular Imager FX and quantified using Quantity One software (Bio-Rad).

\section{Western blot analysis}

A total of $50 \mu \mathrm{g}$ of nuclear or cytoplasmic proteins, prepared as described previously [7,34], were separated by electrophoresis on SDS/8\% polyacrylamide gels and transferred to Hybond nitrocellulose membranes (Amersham Biosciences) using Novex ${ }^{\circledR}$ Western Transfer apparatus (Invitrogen). STAT5a and STAT5b proteins were detected by incubation of the membranes with anti-STAT5a- and anti-STAT5b-specific rabbit antibodies kindly provided by Dr Frederic Verdier (INSERM U363, Paris, France) [35]. Nuclear extracts from UT7 cells (kindly provided by Dr Frederic Verdier) overexpressing STAT5a and STAT5b proteins were used as a positive control. Immunoreactive bands were revealed following incubation with a goat anti-rabbit horseradish peroxidase-conjugated secondary IgG (Sigma) using the chemiluminescence ECL ${ }^{\circledR}$-plus kit (Amersham Life Sciences). Quantification was performed relative to $\beta$-actin detected using a specific antibody obtained from Sigma.

\section{RT (reverse transcriptase)-PCR analysis of STAT5a mRNA level}

For RT-PCR analysis, total cellular RNA was extracted from RAW 264.7 macrophages $\left(10^{7}\right.$ cells) using TRIzol ${ }^{\circledR}$ reagent (Invitrogen, Carlsbad, CA, U.S.A.) according to the manufacturer's protocol. Total RNA ( $2 \mu \mathrm{g})$ was used for reverse transcription with superscript II RNAse H RT (Invitrogen) in a $30 \mu \mathrm{l}$ reaction mixture incubated at $45^{\circ} \mathrm{C}$ for $1 \mathrm{~h}$. Of this reaction mixture, $2 \mu \mathrm{l}$ were then used for PCR amplification with Platinum Pfx DNA Polymerase (Invitrogen), using oligonucleotide primers specific for STAT5a: forward: 5'-CCGTGGGATGCTATTGACTT3', reverse: 5'-ACGTGTTCTGGAGCTGTGTG-3'. PCR products were analysed on $2 \%$ agarose gels run with TBE (Tris/borate/ EDTA; $45 \mathrm{mM}$ Tris/borate and $1 \mathrm{mM}$ EDTA) buffer and stained with ethidium bromide. The specific band of $169 \mathrm{bp}$ was quantified with a Molecular Imager using Quantity One software (Bio$\mathrm{Rad}$ ) and normalized to a $489 \mathrm{bp}$ fragment of the GAPDH (glyceraldehyde-3-phosphate dehydrogenase) housekeeping gene amplified from duplicate samples using the forward primer 5'-GACCACAGTCCATGCCATCAC-3' and the reverse primer 5'-TCCACCACCCTGTTGCTGTAG-3'.

\section{Real-time quantitative RT-PCR}

STAT5a mRNA levels in RAW 264.7 cells were measured by realtime quantitative RT-PCR using a Light Cycler (Roche Diagnostics, Mannheim, Germany). The same cDNA templates and primers as those described above were used. Detection of amplification products was carried out using SYBR Green (Roche) as described previously [36]. To confirm amplification specificity, the PCR products from each primer pair were subjected to melting- curve analysis and subsequent agarose-gel electrophoresis. For data analysis, Light Cycler 3.5 Software was used [36]. Quantification was performed relative to GAPDH control reactions.

\section{Statistical analysis}

For statistical evaluation, one-way ANOVA was applied. For estimation of the significance of difference between arithmetic means, the Scheffe test was used. All calculations were done using Statgraphics Plus 6.0 software.

\section{RESULTS \\ Identification of putative binding sites for TFs regulated by NO and iron in the IRP1 promoter}

The -2790 to +90 bp fragment of the mouse IRPI gene (GenBank ${ }^{\circledR}$ accession no. AJ427344) was searched for potential binding sites for TFs regulated by NO and/or changes in intracellular iron level using the TESS (Transcription Element Search System) software (http://www.cbil.upenn.edu/tess/) and TRANSFAC database (http://www.gene-regulation.com/pub/ databases.html\#transfac). We found the following conserved motifs: one Sp1 sequence, 55 bp away from the transcription start site; one MRE sequence, $128 \mathrm{bp}$ away from the transcription start site; and one GAS motif, a potential binding site for STAT family proteins, $1345 \mathrm{bp}$ upstream of the transcription start site (Figure 1A). All identified sequences are also present in the human IRPI promoter $\left(\mathrm{GenBank}^{\circledR}\right.$ accession no. AL161783) at approximately the same distances from the transcription start site (Figure 1A).

\section{Predominant role of the GAS sequence in the inhibition of mouse IRP1 promoter activity by NO in transfected HuH7 cells}

To perform functional studies of the IRPI promoter and analyse its regulation by $\mathrm{NO}$, three luciferase-based reporter constructs containing sub-fragments of the IRPI promoter sequence, with sizes ranging from 195 to $624 \mathrm{bp}$ (Figure 1B), were transiently transfected into $\mathrm{HuH} 7$ cells and the cells were grown for $48 \mathrm{~h}$ with or without DETA/NO as an NO donor. The pGL3 control vector expressing the luciferase under the control of the SV40 promoter was highly expressed in these cells and there was a $60 \%$ reduction in luciferase activity following DETA/NO treatment (results not shown), as previously reported [37]. Transient transfections of HuH7 cells with the pGL2-IRP1P0.1 construct containing the minimal promoter fragment showed that the basal luciferase activity produced by this construct was very low and treatment of the cells for $48 \mathrm{~h}$ with a chemical NO donor (DETA/NO, $250 \mu \mathrm{M}$ ), induced a statistically significant 2 -fold reduction $(P<0.05)$ in luciferase activity (Figure 1C). The longer $605 \mathrm{bp}$ fragment from pGL2-IRPIP0.2 construct containing both Sp1 and MRE showed a higher transcriptional activity, with a 3-4-fold increase in luciferase activity as compared with $\mathrm{HuH} 7$ pGL2-IRP1P0.1transfected cells. However, the NO treatment only induced a moderate decrease in luciferase activity. Another construct was made by adding an oligonucleotide with the GAS sequence upstream of pGL2-IRPIP0.2 (Figure 1B). The basal activity produced by the pGL2-IRP1P0.3 plasmid was the highest among all the analysed IRPI promoter-luciferase constructs. Treatment with DETA/NO of pGL2-IRP1P0.3 vector-transfected HuH7 cells revealed a substantial $(90 \%)$ inhibition of luciferase activity compared with basal conditions (Figure 1C). Considering that the pGL2-IRP1P0.3 construct was generated by the addition, upstream of the $605 \mathrm{bp}$ fragment in pGL2-IRPIP0.2, of a short $19 \mathrm{bp}$ fragment comprising the upstream GAS sequence from the 


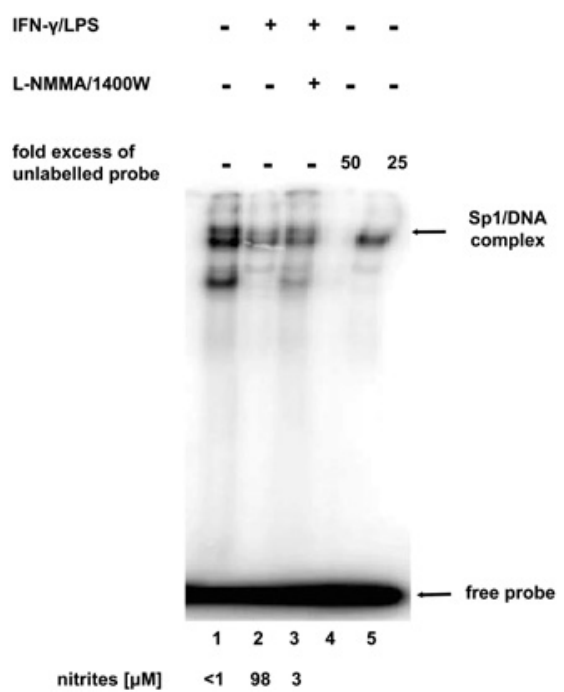

B

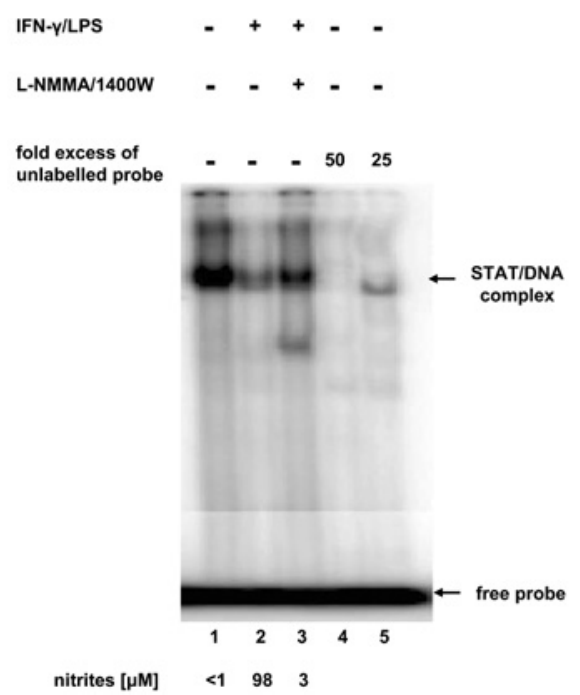

C

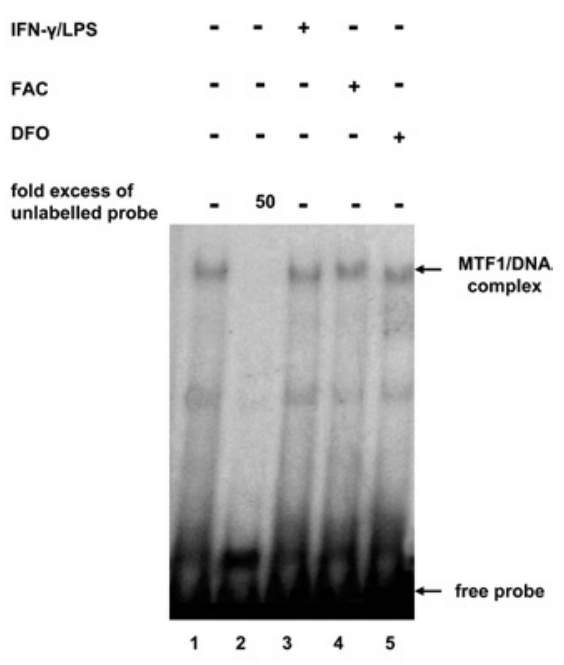

Figure 2 Effect of endogenous NO on Sp1-, STAT- and MTF1-DNA binding activity in mouse 264.7 macrophages

Nuclear protein $(2 \mu \mathrm{g})$ and a molar excess of ${ }^{32} \mathrm{P}$-labelled probes containing the (A) Sp1, (B) GAS or (C) MRE sequences from the mouse IRP1 promoter were used in EMSA analysis as described in the Experimental section. Cultured RAW 264.7 macrophages were stimulated for $16 \mathrm{~h}$ with 20 units/ml IFN- $\gamma$ plus $50 \mathrm{ng} / \mathrm{ml}$ LPS in the presence or absence of $1 \mathrm{mM} \mathrm{L-NMMA}$ and $25 \mu \mathrm{M} 1400 \mathrm{~W}$ (A, B). NO production was measured by assaying nitrites using the Griess method in culture supernatants of stimulated and unstimulated cells. RAW 264.7 macrophages were incubated with $250 \mu \mathrm{M}$ DF0 and/or $100 \mu \mathrm{M} \mathrm{FAC} \mathrm{for} 24 \mathrm{~h}$ (C). To check the specificity of the DNA binding, unlabelled competitor fragments were added to reaction mixtures at 25- and 50-fold molar excess over the labelled probes. Reaction products were separated by electrophoresis on non-denaturing $6 \%$ polyacrylamide gels. The experiments were performed at least three times, and representative gels are shown. The positions of the DNA-protein complexes and the free probes are indicated.

IRPI promoter, this result suggests the effective and predominant role of the STAT-binding site in both the basal transcriptional activity and the NO-dependent regulation of the mouse IRPI promoter.

\section{NO inhibits Sp1- and STAT-DNA binding, but has no effect on MTF1 DNA binding}

Since the Sp1- and the STAT-binding sites appear to be functional and play a role in NO-mediated down-regulation of the IRPI promoter we decided to study the effect of NO on the DNA binding activity of Sp1 and STATs in RAW 264.7 macrophage nuclear extracts. We performed EMSAs using short DNA probes comprising the Sp1-binding site or the GAS sequence of the mouse IRPI promoter. The specificity of the constitutive DNA-binding reactions (Figures $2 \mathrm{~A}$ and $2 \mathrm{~B}$, lanes 1 ) was confirmed by competition with a 50-fold (Figures $2 \mathrm{~A}$ and $2 \mathrm{~B}$, lanes 4) and a 25 fold (Figures 2A and 2B, lanes 5) molar excess of the unlabelled probes. NO production was stimulated by treating the cells with IFN- $\gamma$ and LPS and was followed by measuring nitrite (a stable oxidation product of $\mathrm{NO}$ ) released in the culture medium (as indicated below Figures $2 \mathrm{~A}$ and $2 \mathrm{~B}$ ). The formation of Sp1-DNA (Figure 2A, lane 2) and STAT-DNA (Figure 2B, lane 2) complexes in reactions including nuclear extracts from NO-producing RAW 264.7 cells was markedly reduced as compared with those using extracts from control cells (Figures $2 \mathrm{~A}$ and 2B, lanes 1 ). This decrease was 65 and $47 \%$ respectively as assessed by densitometric analysis. The effect of NO was largely reversed when EMSAs were performed using nuclear extracts from stimulated macrophages treated with $1400 \mathrm{~W}$ and L-NMMA, two NOS2 inhibitors (Figures 2A and 2B, lanes 3). EMSA was also used to visualize nuclear protein complexes with the MRE sequence overlapping the -128 to -135 region of the IRPI promoter in NO-producing macrophages (Figure 2C). The specificity of the basal MTF1 binding to MRE in control RAW 264.7 macrophages
(Figure 2C, lane 1) was confirmed by competition with a 50-fold excess (Figure 2C, lane 2) of the unlabelled MRE probe. NO has been shown to affect LIP levels in various cell types [53,54], and thus may indirectly influence the DNA-binding activity of MTF1, a TF known to bind MRE and to be regulated by heavy metals [38]. However, we detected no changes in MTF1 binding to MRE in RAW macrophages using nuclear extracts from cells stimulated for NO synthesis with IFN- $\gamma /$ LPS (Figure 2C, lane 3). Similarly, in macrophages incubated either with FAC (Figure 2C, lane 4) or DFO, an iron chelator (Figure 2C, lane 5), the level of MTF1-DNA complexes was unaffected compared with control cells, clearly indicating that fluctuations in intracellular iron level had no effect on MTF1-DNA binding.

\section{NO decreases STAT5a and STAT5b protein levels in the cytosol and nuclei of NO-producing macrophages}

The mechanism underlying the NO-mediated decrease in STATDNA complex formation and inhibition of transcriptional activity of the mouse IRPI promoter, could involve impaired nuclear translocation of STAT proteins in response to NO. Since the STAT protein family comprises seven members showing apparently similar binding affinity for the GAS sequence [39], we focused our attention on the STAT5 proteins whose involvement in signalling pathways inhibited by NO is well recognized $[32,40]$. We measured STAT proteins in cytosolic and nuclear extracts of RAW 264.7 macrophages, using nuclear extracts from UT7 cells overexpressing STAT5a and STAT5b as positive controls. The results showed a marked reduction in STAT5b protein levels in nuclei of NO-producing RAW 264.7 macrophages as compared with control macrophages (Figure 3, upper panel, lane 2 versus lane 1). However, an even more drastic reduction in both STAT5a and STAT5b proteins, i.e. an almost total absence (Figure 3, lower panel, lane 2), was observed in the cytosol, which indicates that impaired translocation is not the reason for the reduction in 


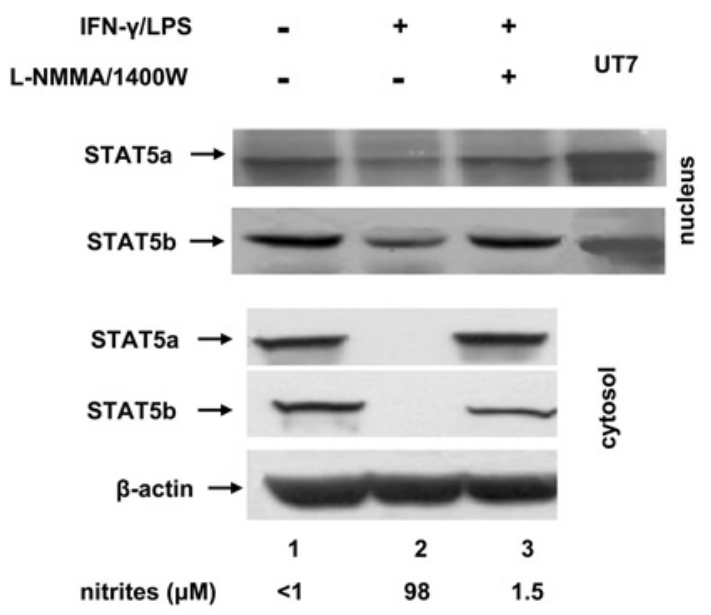

Figure 3 Reduced STAT5a and STAT5b protein levels in NO-producing RAW 274.7 macrophages

RAW 264.7 macrophages were stimulated for $16 \mathrm{~h}$ with 20 units/ml IFN- $\gamma$ plus $50 \mathrm{ng} / \mathrm{ml}$ LPS in the presence or absence of $1 \mathrm{mM} \mathrm{L-NMMA}$ and $25 \mu \mathrm{M}$ 1400W. NO production was measured by assaying nitrite in the culture medium. STAT5a and STAT5b levels were assessed in nuclear (upper panel) and cytosolic (lower panel) extracts by Western blotting as described in the Experimental section. To assist identification of STAT5a and STAT5b bands, nuclear extracts from UT7 cells overexpressing STAT5a and STAT5b proteins (a gift from Dr Frederic Verdier) were electrophoresed on the same gels. Each blot is representative of three blots showing similar results.

STAT-DNA complex formation. This characteristic pattern of changes in STAT protein levels in these two cellular compartments was specific for NO-producing cells and it was largely reversed when NO synthesis had been abolished by inhibitors of NOS2 (Figure 3, lane 3).

\section{LPS/IFN- $\gamma$-induced reduction of STAT5a expression is not due to $\mathrm{mRNA}$ down-regulation}

We next examined whether this reduction in the amount of STAT5a protein resulted from a decrease in the level of the corresponding mRNA transcript. Both semi-quantitative RTPCR (Figures 4A and 4B) and real-time quantitative RT-PCR (Figure 4C) consistently showed that STAT5a mRNA expression in NO-producing RAW 264.7 macrophages was unchanged relative to control cells or in comparison with macrophages in which NO synthesis was severely reduced. These analyses suggest that the substantial decrease in STAT5a protein content in response to NO is not due to less efficient transcription of the STAT5 $a$ gene or decreased stability of STAT5a mRNA.

\section{DISCUSSION}

Most studies on the regulation of IRP1 activities have been focused on post-translational mechanisms underlying the insertion/extrusion of a [4Fe-4S] cluster into/from the IRP1 molecule $[5,13]$. However, we have recently shown that changes in intracellular protein IRP1 levels could account for the observed modifications in its IRE-binding affinity [16,41,42]. It has long been known that in mammals, IRP1 displays highly variable expression patterns in different tissues [43]. The biological significance of regulation of IRP1 expression at the protein level are indicated by studies on NO-producing macrophages, in which NO was shown not only to induce IRP1 RNA binding activity but also to reduce IRP1 protein level [16]. The aim of the present
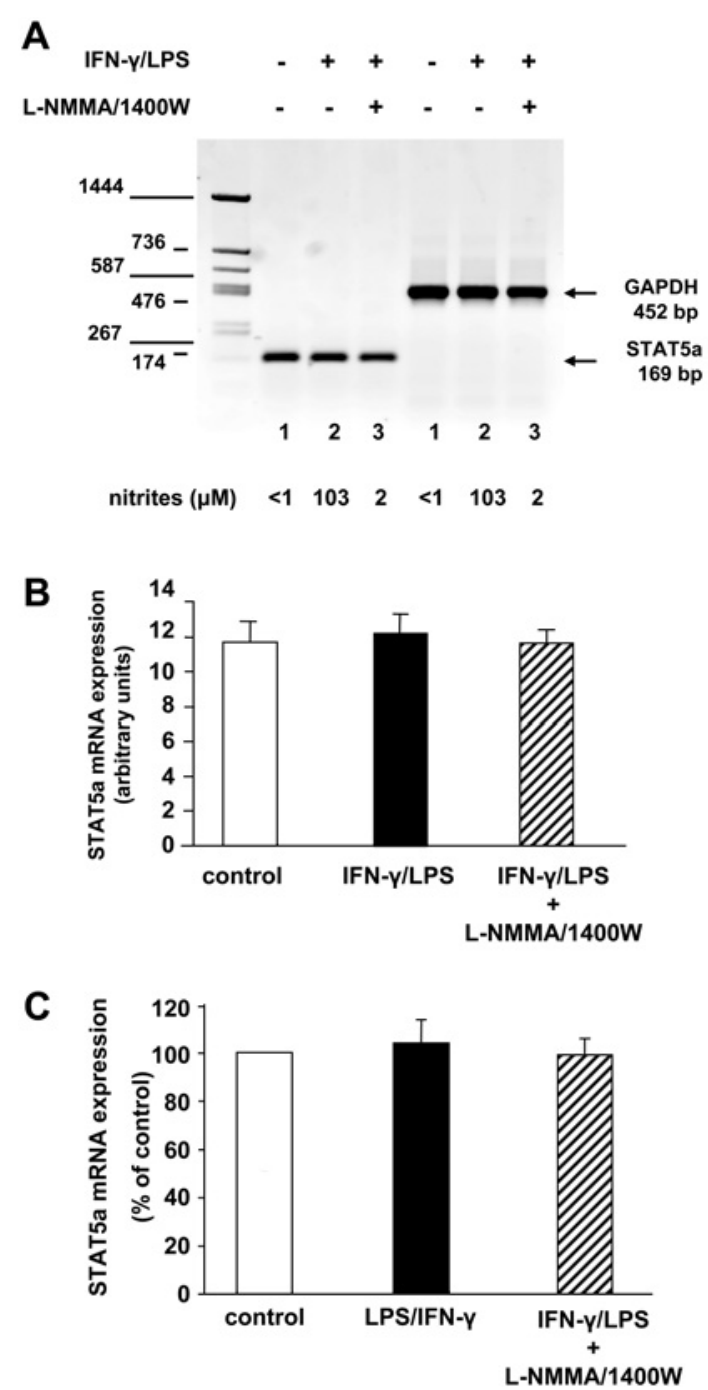

Figure 4 Analysis of STAT5a mRNA abundance in NO-producing RAW 264.7 macrophages by RT-PCR

RAW 264.7 macrophages were stimulated for $16 \mathrm{~h}$ with $20 \mathrm{units} / \mathrm{ml}$ IFN- $\gamma$ plus $50 \mathrm{ng} / \mathrm{ml}$ LPS in the presence or absence of $1 \mathrm{mM}$ L-NMMA and $25 \mu \mathrm{M} 1400 \mathrm{~W}$. N0 production was measured by assaying nitrite in the culture medium. RNA was isolated from harvested cells and used for semi-quantitative RT-PCR as described in the Experimental section. The GAPDH amplicon was used as a control for the amount of CDNA used in the PCR reactions. The experiments were performed three times, and a representative result is shown $(\mathbf{A})$. PCR product bands were quantified using a Molecular Imager and the means \pm S.D. are plotted in arbitrary units $(n=3)$ (B). STAT5a mRNA abundance in RAW 264.7 macrophages was measured by real-time RT-PCR (C). Each column represents the mean ( \pm S.D.) for three amplification reactions performed on a single cDNA sample reverse transcribed from RNA prepared from cells from three independent experiments. The level of STAT5b mRNA in control macrophages was assigned the $100 \%$ value.

study was to investigate the transcriptional regulation of IRPI in response to $\mathrm{NO}$ and to identify regulatory elements within the IRPI promoter responsible for NO-dependent inhibition of IRPI expression. Although previous studies have reported no changes in the total amount of immunologically detectable IRP1 following treatment of various cell types with iron sources and iron chelators [44-46], recent data from closely related mouse lymphoblastic cell lines show a close quantitative correlation between the amount of IRP1 and LIP levels [41]. Furthermore, it has been demonstrated that hepatic IRP1 protein levels in haemochromatosis patients are altered [47]. With this in mind, we also attempted to test the influence of iron on transcriptional 
regulation of the IRPI gene. Using bioinformatics software, the mouse $I R P I$ promoter sequence was screened for putative binding sites for NO- and iron-dependent transcriptional regulators. We identified potential binding sites for $\mathrm{Sp} 1$ and STAT proteins, two TFs known to be molecular targets for NO [30,32,40]. We also found one potential MRE sequence similar to those present in the promoter region of genes encoding metallothionein- $\mathrm{II}_{\mathrm{A}}$ [48], a heavy-metal binding protein, or bivalent metal transporter 1 [49], a mediator of apical iron uptake in duodenal enterocytes and iron transfer from the transferrin receptor endosomal cycle into the cytosol.

To gain further insights into the role of the GAS and Sp1 sequences in NO-mediated repression of the mouse IRPI gene, we transiently transfected human hepatoma $\mathrm{HuH} 7$ cells with constructs containing fragments of the mouse IRPI promoter fused to the luciferase reporter gene. The minimal $55 \mathrm{bp}$ promoter had a very low basal transcriptional activity, which was reduced by NO production. The mouse IRPI promoter lacks typical TATA or CCAAT boxes. In many genes lacking a TATA box, a proximally positioned Sp1 site may be critical for basal transcription and can determine the start site [50]. Our results indicate that the proximal Sp1 binding site is of limited importance for basal transcription of IRPI. However, NO treatment of the transfected cells induced a significant reduction in basal transcriptional activity, and accordingly, nuclear extracts from activated macrophages reduced the DNA binding activity of $\mathrm{Sp} 1$. This result is in line with those of previous studies demonstrating inhibition or a lack of DNA binding by native $\mathrm{Sp} 1$ derived from different cell types treated with chemical NO donors [30,51,52]. It is important to note that the NO-mediated loss of Sp1 DNA binding activity may result in either a decrease [30,51] or an increase [52] in gene expression, depending on whether this factor is acting as an activator or a repressor of transcription. Thus the results of our EMSA experiments are not conclusive concerning the role of Sp1 in NO-dependent down-regulation of IRPI gene transcription.

Transfection of $\mathrm{HuH7}$ cells with the second construct, pGL2IRPIP0.2, containing both Sp1 and MRE sequences, resulted in substantially higher basal transcriptional activity, but no decrease in luciferase activity in response to NO. Accordingly, there was no change in the DNA-binding activity to the MRE sequence in response to fluctuations in cellular iron content or to NO, recently shown to alter LIP level $[53,54]$. This result agrees with those of previous studies showing that interaction of MTF1 with multiple MREs present in 5'-regulatory regions of several genes is induced by heavy metals other than iron [48]. It is thus possible that the effect of MTF1-mediated modulation of gene transcription may only involve genes containing several copies of the MRE sequence in their promoters [48]. The insensitivity of the binding of MTF-1, a zinc sensor protein [55], to DNA in response to NO may result from the opposite effects of NO on zinc finger-dependent transcription. Zinc finger disruption by NO may inhibit or activate transcription, depending on the structure of the promoter [56]. NO-mediated inhibition of zinc finger-dependent gene transcription [51] may be counteracted by an indirect effect resulting from NO-mediated release of zinc bound to cytosolic low-molecular mass chelators. The activation of MTF1-DNA binding by such a mechanism has been reported in response to $\mathrm{Cd}$ (cadmium) and oxidative stress upon $\mathrm{Cd}$ binding or oxidation of metal-co-ordinating thiolates respectively [55].

Functional analysis of the IRPI promoter using the third construct, pGL2-IRPIP0.3, clearly showed that the GAS sequence plays a major role in both the basal expression level and NOdependent regulation of the IRPI gene. It should be stressed that only a $19 \mathrm{bp}$ fragment comprising the GAS sequence from the IRPI promoter was added to pGL2-IRPIP0.2 in order to generate pGL2-IRPIP0.3. The demonstration that NO produced a $70 \%$ decrease in binding of STAT proteins to the GAS sequence located in the IRPI promoter strongly suggests the involvement of this family of TFs in the regulation of IRPI gene expression by NO. In agreement with this finding, negative gene regulation in response to NO by STAT5 [32,40], and also by STAT1 [57], has been reported for several cellular functions in various cell types. Taken together, the results of the EMSAs and those from the functional activity assays indicate that the GAS sequence is an important regulatory element responsible for down-regulation of IRPI expression by NO.

The GAS sequence was originally identified as an element required for the rapid transcriptional induction of genes in response to IFN- $\gamma$ [58]. The protein complex binding to GAS sequences in IFN- $\gamma$-treated cells is a dimer of STAT1, the prototype of the STAT protein family. To date, seven different STATs have been recognized, six of which bind to a GAS element [59]. Because STAT5 proteins are those most frequently shown to take part in nuclear signalling in response to NO $[32,40]$, we investigated the roles of STAT5a and STAT5b in the mechanism underlying NO-dependent down-regulation of IRPI. Although these two STAT5 proteins share a high degree of amino acid sequence identity and show considerable functional overlap they are not functionally redundant [59]. According to a general model for receptor-mediated activation of STAT, there are several cytokine receptor-associated Janus kinases that induce dimerization, nuclear translocation and DNA binding of STAT through tyrosine phosphorylation [39]. To identify the mechanism through which NO exerts its repressive effect on IRPI expression via the GAS sequence, we initially investigated whether it is associated with impaired nuclear translocation of STAT5. Endogenous NO was found to markedly reduce nuclear levels of both STAT5a and STAT5b in RAW 264.7 macrophages. A similar effect was observed when RAW 264.7 cells were incubated for $18 \mathrm{~h}$ with DETA/NO (results not shown). Surprisingly, an identical analysis of cytosolic extracts from RAW 264.7 macrophages, activated for NO synthesis, showed an even greater decrease in STAT5a and STAT5b content than that observed in nuclei. The results of these Western blot analyses indicated an overall decline in STAT5 protein levels rather than one restricted to nuclei. The reduction in the amount of STAT5a at the protein level was not associated with a decrease in the expression or stability of the transcript, since STAT5a mRNA levels were not influenced by NO. Taken together, our results on STAT5a mRNA and protein levels in NO-producing macrophages strongly suggest that NO sensitizes STAT5 proteins for accelerated degradation. This conclusion is supported by the description [60] of a proteosome proteolytic pathway for STAT5 and the proposal that this plays a role in downregulation of STAT5 signalling. A hypothetical mechanism for the down-regulation of STAT5 activity by NO may involve nitration of key tyrosine residue(s) in STAT5 molecules and subsequent proteolytic degradation by the ubiquitin-proteosome pathway as has been described for other proteins [61].

The findings of the present study permit us to outline a plausible regulatory loop between STAT family proteins, NO and IRP1. TFs from the STAT family participate in signal transduction initiated by IFN- $\gamma$, leading to the activation of NOS 2 expression and subsequent high output of NO [62]. The action of NO rapidly generates the RNA binding form of IRP1 [13], which downregulates ferritin and up-regulates transferrin receptor via a posttranscriptional mechanism, thus contributing to the expansion of the catalytically active free iron pool. On the other hand, NO would promote degradation of STAT5 proteins, which inhibits expression of the IRPI gene at the transcriptional level. The biological importance of this regulation may be in minimizing the 
NO-dependent reaction that boosts RNA binding by IRP1 and, consequently, attenuates the NO-induced rise in the LIP, a major factor in increasing the likelihood of oxidative injury.

Finally, a question arises as to the possible role of STAT5-driven regulation of IRP1 described here, in the cross-talk between NO and iron in cells. It is conceivable to propose that iron released from iron-containing proteins upon NO enters LIP and transits through the cytosolic compartment before being transported across the cellular membrane as nitrosyl-iron complexes by multidrug resistance-associated protein 1 , as suggested recently [22]. This so-called transient iron may be easily taken up by ferritin, a main regulator of LIP levels [63]. By decreasing the amount of IRP1 via STAT5, NO minimizes its potential to inhibit ferritin expression at the post-transcriptional level, and may thus maintain and safeguard the capacity of this protein to sequester potentially harmful free iron.

This work was supported by a NATO (North Atlantic Treaty Organisation) Collaborative Linkage grant (PST.CGL 979519). We thank John Gittins for a critical reading of this paper.

\section{REFERENCES}

1 Hentze, M. W., Muckenthaler, M. U. and Andrews, N. C. (2004) Balancing acts: molecular control of mammalian iron metabolism. Cell 117, 285-297

2 Meyron-Holtz, E. G., Ghosh, M. C., Iwai, K., LaVaute, T., Brazzolotto, X., Berger, U. V., Land, W., Olivierre-Wilson, H., Grinberg, A., Love, P. et al. (2004) Genetic ablations of iron regulatory proteins 1 and 2 reveal why iron regulatory protein 2 dominates iron homeostasis. EMBO J. 23, 386-395

3 Cooperman, S. S., Meyron-Holtz, E. G., Olivierre-Wilson, H., Ghosh, M. C., McConnell, J. P. and Rouault, T. A. (2005) Microcytic anemia, erythropoietic protoporphyria, and neurodegeneration in mice with targeted deletion of iron-regulatory protein 2. Blood 106, 1084-1091

4 Galy, B., Ferring, D., Minana, B., Bell, O., Janser, H. G., Muckenthaler, M., Schumann, K. and Hentze, M. W. (2005) Generation of conditional alleles of the murine Iron Regulatory Protein (IRP)-1 and -2 genes. Blood 106, 2580-2589

5 Bouton, C. and Drapier, J. C. (2003) Iron regulatory proteins as NO signal transducers. Science STKE 2003, 182

6 Meyron-Holtz, E. G., Ghosh, M. C. and Rouault, T. A. (2004) Mammalian tissue oxygen levels modulate iron-regulatory protein activities in vivo. Science 306, 2087-2090

7 Drapier, J. C., Hirling, H., Wietzerbin, J., Kaldy, P. and Kühn, L. C. (1993) Biosynthesis of nitric oxide activates iron regulatory factor in macrophages. EMBO J. 12, 3643-3649

8 Weiss, G., Goossen, B., Doppler, W., Fuchs, D., Pantopoulos, K., Werner-Felmayer, G., Wachter, H. and Hentze, M. W. (1993) Translational regulation via iron-responsive elements by the nitric oxide/NO-synthase pathway. EMBO J. 12, 3651-3657

9 Martins, E. A., Robalinho, R. L. and Meneghini, R. (1995) Oxidative stress induces activation of a cytosolic protein responsible for control of iron uptake. Arch. Biochem. Biophys. 316, 128-134

10 Pantopoulos, K. and Hentze, M. W. (1995) Rapid responses to oxidative stress mediated by iron regulatory protein. EMBO J. 14, 101-108

11 Schalinske, K. L., Anderson, S. A., Tuazon, P. T., Chen, O. S., Kennedy, M. C. and Eisenstein, R. S. (1997) The iron-sulfur cluster of iron regulatory protein 1 modulates the accessibility of RNA binding and phosphorylation sites. Biochemistry 36, 3950-3958

12 Hanson, E. S. and Leibold, E. A. (1998) Regulation of iron regulatory protein 1 during hypoxia and hypoxia/reoxygenation. J. Biol. Chem. 273, 7588-7593

13 Drapier, J. C., Bouton, C. and Oliveira, L. (2001) Redox modulation of iron regulatory proteins by nitric oxide and peroxynitrite. In Nitric Oxide Biology and Pathobiology (Ignarro, L. J., ed.), pp. 315-328, Academic Press, San Diego

14 Soum, E., Brazzolotto, X., Goussias, C., Bouton, C., Moulis, J. M., Mattioli, T. A. and Drapier, J. C. (2003) Peroxynitrite and nitric oxide differently target the iron-sulfur cluster and amino acid residues of human iron regulatory protein 1 . Biochemistry $\mathbf{4 2 , 7 6 4 8 - 7 6 5 4}$

15 Gonzalez, D., Drapier, J. C. and Bouton, C. (2004) Endogenous nitration of iron regulatory protein-1 (IRP-1) in nitric oxide-producing murine macrophages: further insight into the mechanism of nitration in vivo and its impact on IRP-1 functions. J. Biol. Chem. 279, 43345-43351

16 Oliveira, L. and Drapier, J. C. (2000) Down-regulation of iron regulatory protein 1 gene expression by nitric oxide. Proc. Natl. Acad. Sci. U.S.A. 97, 6550-6555

17 Watts, R. N., Ponka, P. and Richardson, D. R. (2003) Effects of nitrogen monoxide and carbon monoxide on molecular and cellular iron metabolism: mirror-image effector molecules that target iron. Biochem. J. 369, 429-440
18 Lipiński, P. and Drapier, J. C. (1997) Interplay between ferritin metabolism, reactive oxygen species and nitric oxide. J. Biol. Inorg. Chem. 2, 559-566

19 Recalcati, S., Taramelli, D., Conte, D. and Cairo, G. (1998) Nitric oxide-mediated induction of ferritin synthesis in $\mathbf{J} 774$ macrophages by inflammatory cytokines: role of selective iron regulatory protein-2 downregulation. Blood 91, 1059-1066

20 Wang, J., Chen, G. and Pantopoulos, K. (2005) Nitric oxide inhibits the degradation of IRP2. Mol. Cell. Biol. 25, 1347-1353

21 Hibbs, Jr, J. B., Taintor, R. R. and Vavrin, Z. (1984) Iron depletion: possible cause of tumor cell cytotoxicity induced by activated macrophages. Biochem. Biophys. Res. Commun. 123, 716-723

22 Watts, R. N., Hawkins, C., Ponka, P. and Richardson, D. R. (2006) Nitrogen monoxide (NO)-mediated iron release from cells is linked to NO-induced glutathione efflux via multidrug resistance-associated protein 1. Proc. Natl. Acad. Sci. U.S.A. 103, 7670-7675

23 Henry, Y., Lepoivre, M., Drapier, J. C., Ducrocq, C., Boucher, J. L. and Guissani, A. (1993) EPR characterization of molecular targets for $\mathrm{NO}$ in mammalian cells and organelles. FASEB J. 7, 1124-1134

24 Vanin, A. F. (1998) Dinitrosyl iron complexes and S-nitrosothiols are two possible forms for stabilization and transport of nitric oxide in biological systems. Biochemistry (Mosc.) 63, 782-793

25 Durante, W., Kroll, M. H., Christodoulides, V., Peyton, K. J. and Schafer, A. I. (1997) Nitric oxide induces heme oxygenase-1 gene expression and carbon monoxide production in vascular smooth muscle cells. Circ. Res. 80, 557-564

26 Bouton, C. and Demple, B. (2000) Nitric oxide-inducible expression of heme oxygenase-1 in human cells. Translation-independent stabilization of the mRNA and evidence for direct action of nitric oxide. J. Biol. Chem. 275, 32688-32693

27 Bogdan, C. (2001) Nitric oxide and the regulation of gene expression. Trends Cell Biol. 11, 66-75

28 Shin, W. S., Hong, Y. H., Peng, H. B., De Caterina, R., Libby, P. and Liao, J. K. (1996) Nitric oxide attenuates vascular smooth muscle cell activation by interferon-gamma. The role of constitutive NF- $\kappa$ B activity. J. Biol. Chem. 271, 11317-11324

29 Pilz, R. B., Suhasini, M., Idriss, S., Meinkoth, J. L. and Boss, G. R. (1995) Nitric oxide and CGMP analogs activate transcription from AP-1-responsive promoters in mammalian cells. FASEB J. 9, 552-558

30 Sellak, H., Yang, X., Cao, X., Cornwell, T., Soff, G. A. and Lincoln, T. (2002) Sp1 transcription factor as a molecular target for nitric oxide- and cyclic nucleotide-mediated suppression of cGMP-dependent protein kinase-l $\alpha$ expression in vascular smooth muscle cells. Circ. Res. 90, 405-412

31 Metzen, E., Zhou, J., Jelkmann, W., Fandrey, J. and Brune, B. (2003) Nitric oxide impairs normoxic degradation of HIF- $1 \alpha$ by inhibition of prolyl hydroxylases. Mol. Biol. Cell $\mathbf{1 4}$ 3470-3481

32 Bingisser, R. M., Tilbrook, P. A., Holt, P. G. and Kees, U. R. (1998) Macrophage-derived nitric oxide regulates $T$ cell activation via reversible disruption of the Jak3/STAT5 signaling pathway. J. Immunol. 160, 5729-5734

33 Andrews, N. C. and Faller, D. V. (1991) A rapid micropreparation technique for extraction of DNA-binding proteins from limiting numbers of mammalian cells. Nucleic Acids Res. 19, 2499

34 Roe, A. L., Howard, G. and Blouin, R. A. (1998) Characterization of nuclear protein binding (AP-1, GR, and STAT) in the genetically obese (fa/fa) Zucker rat. Life Sci. 15, 1339-1346

35 Verdier, F., Rabionet, R., Gouilleux, F., Beisenherz-Huss, C., Varlet, P., Mulle, 0., Mayeux, P., Lacombe, C., Gisselbrecht, S. and Chretien, S. (1998) A sequence of the CIS gene promoter interacts preferentially with two associated STAT5A dimers: a distinct biochemical difference between STAT5A and STAT5B. Mol. Cell. Biol. 18, 5852-5860

36 Simpson, D. A. C., Feeney, S., Boyle, C. and Sitt, A. W. (2000) Retinal VEGF mRNA measured by SYBR green I fluorescence: a versatile approach to quantitative PCR. Mol. Vision 6, 178-183

37 Fan, X., Roy, E., Zhu, L., Murphy, T. C., Kozlowski, M., Nanes, M. S. and Rubin, J. (2003) Nitric oxide donors inhibit luciferase expression in a promoter-independent fashion. J. Biol. Chem. 278, 10232-10238

38 Radtke, F., Georgiev, O., Muller, H. P., Brugnera, E. and Schaffner, W. (1995) Functional domains of the heavy metal-responsive transcription regulator MTF-1. Nucleic Acids Res. 23, 2277-2286

39 Horvath, C. M. (2000) STAT proteins and transcriptional responses to extracellular signals. Trends Biochem. Sci. 25, 496-502

40 Mazzoni, A., Bronte, V., Visintin, A., Spitzer, J. H., Apolloni, E., Serafini, P., Zanovello, P. and Segal, D. M. (2002) Myeloid suppressor lines inhibit T cell responses by an NO-dependent mechanism. J. Immunol. 168, 689-695

41 Lipiński, P., Drapier, J. C., Oliveira, L., Retmańska, H., Sochanowicz, B. and Kruszewski, M. (2000) Intracellular iron status as a hallmark of mammalian cell susceptibility to oxidative stress: a study of $\mathrm{L} 5178 \mathrm{Y}$ mouse lymphoma cell lines differentially sensitive to $\mathrm{H}_{2} \mathrm{O}_{2}$. Blood 95, 2960-2966 
42 Starzyński, R. R., Lipiński, P., Drapier, J. C., Diet, A., Smuda, E., Bartłomiejczyk, T., Gralak, M. A. and Kruszewski, M. (2005) Down-regulation of iron regulatory protein 1 activities and expression in superoxide dismutase 1 knock-out mice is not associated with alterations in iron metabolism. J. Biol. Chem. 280, 4207-4212

43 Müllner, E. W., Rothenberger, S., Müller, A. M. and Kühn, L. C. (1992) In vivo and in vitro modulation of the mRNA-binding activity of iron-regulatory factor. Tissue distribution and effects of cell proliferation, iron levels and redox state. Eur. J. Biochem. 208 $597-605$

44 Tang, C. K., Chin, J., Harford, J. B., Klausner, R. D. and Rouault, T. A. (1992) Translational repressor activity is equivalent and is quantitatively predicted by in vitro RNA binding for two iron-responsive element-binding proteins, IRP1 and IRP2. J. Biol. Chem. 267 $24466-24470$

45 Henderson, B. R., Seiser, C. and Kuhn, L. C. (1993) Characterization of a second RNA-binding protein in rodents with specificity for iron-responsive elements. J. Biol. Chem. 268, 27327-27334

46 Guo, B., Phillips, J. D., Yu, Y. and Leibold, E. A. (1995) Iron regulates the intracellular degradation of iron regulatory protein 2 by the proteasome. J. Biol. Chem. $\mathbf{2 7 0}$, 21645-21651

47 Neonaki, M., Graham, D. C., White, K. N. and Bomford, A. (2002) Down-regulation of liver iron-regulatory protein 1 in haemochromatosis. Biochem. Soc. Trans. 30, 726-728

48 Palmiter, R. D. (1994) Regulation of metallothionein genes by heavy metals appears to be mediated by a zinc-sensitive inhibitor that interacts with a constitutively active transcription factor, MTF-1. Proc. Natl. Acad. Sci. U.S.A. 91, 1219-1223

49 Lee, P. L., Gelbart, T., West, C., Halloran, C. and Beutler, E. (1998) The human Nramp2 gene: characterization of the gene structure, alternative splicing, promoter region and polymorphisms. Blood Cells Mol. Dis. 2, 199-215

50 Sauerwald, A., Hoesche, C., Oschwald, R. and Kilimann, M. W. (1990) The 5'-flanking region of the synapsin I gene. A G + C-rich, TATA- and CAAT-less, phylogenetically conserved sequence with cell type-specific promoter function. J. Biol. Chem. $\mathbf{2 6 5}$, 14932-14937

51 Berendji, D., Kolb-Bachofen, V., Zipfel, P. F., Skerka, C., Carlberg, C. and Kroncke, K.D. (1999) Zinc finger transcription factors as molecular targets for nitric oxide-mediated immunosuppression: inhibition of IL-2 gene expression in murine lymphocytes. Mol. Med. 5, 721-730

Received 26 April 2006/11 July 2006; accepted 4 August 2006

Published as BJ Immediate Publication 4 August 2006, doi:10.1042/BJ20060623
52 Wang, S., Wang, W., Wesley, R. A. and Danner, R. L. (1999) A Sp1 binding site of the tumor necrosis factor $\alpha$ promoter functions as a nitric oxide response element. J. Biol. Chem. 274, 33190-33193

53 Lipiński, P., Starzyński, R. R., Drapier, J. C., Bouton, C., Bartłomiejczyk, T., Sochanowicz, B., Smuda, E., Gajkowska, A. and Kruszewski, M. (2005) Induction of iron regulatory protein 1 RNA-binding activity by nitric oxide is associated with a concomitant increase in the labile iron pool: implications for DNA damage. Biochem. Biophys. Res. Commun. 327, 349-355

54 Chenais, B., Morjani, H. and Drapier, J. C. (2002) Impact of endogenous nitric oxide on microglial cell energy metabolism and labile iron pool. J. Neurochem. 81, 615-623

55 Giedroc, D. P., Chen, X. and Apuy, J. L. (2001) Metal response element (MRE)binding transcription factor-1 (MTF-1): structure, function, and regulation. Antioxide Redox Signal. 3, 577-596

56 Kroncke, K. D. (2003) Nitrosative stress and transcription. Biol. Chem. 384, 1365-1377

57 Giustizieri, M. L., Albanesi, C., Scarponi, C., De Pita, 0. and Girolomoni, G. (2002) Nitric oxide donors suppress chemokine production by keratinocytes in vitro and in vivo. Am. J. Pathol. 161, 1409-1418

58 Decker, T., Kovarik, P. and Meinke, A. (1997) GAS elements: a few nucleotides with a major impact on cytokine-induced gene expression. J. Interferon Cytokine Res. 17, 121-134

59 Grimley, P. M., Dong, F. and Rui, H. (1999) Stat5a and Stat5b: fraternal twins of signal transduction and transcriptional activation. Cytokine Growth Factor Rev. 10, 131-157

60 Wang, D., Moriggl, R., Stravopodis, D., Carpino, N., Marine, J. C., Teglund, S., Feng, J. and Ihle, J. N. (2000) A small amphipathic $\alpha$-helical region is required for transcriptional activities and proteasome-dependent turnover of the tyrosine-phosphorylated Stat5. EMBO J. 19, 392-399

61 Schopfer, F. J., Baker, P. R. and Freeman, B. A. (2003) NO-dependent protein nitration: a cell signaling event or an oxidative inflammatory response? Trends Biochem. Sci. 28, 646-654

62 lanchette, J., Jaramillo, M. and Olivier, M. (2003) Signalling events involved in interferon-gamma-inducible macrophage nitric oxide generation. Immunology 108, 513-522

63 Picard, V., Epsztejn, S., Santambrogio, P., Cabantchik, Z. I. and Beaumont, C. (1998) Role of ferritin in the control of the labile iron pool in murine erythroleukemia cells. J. Biol. Chem. 273, 5382-5386 